\title{
Effect of Zofenopril on regeneration of sciatic nerve crush injury in
} a rat model

\author{
Ali Murat Kalender*1, Ali Dogan², Vedat Bakan³, Huseyin Yildiz ${ }^{4}$ \\ Mehmet Ata Gokalp ${ }^{2}$ and Mahmut Kalender ${ }^{5}$
}

\begin{abstract}
Address: ${ }^{1}$ Department of Orthopedics and Traumatology, Kahramanmaras Sutcu Imam University, Medical Faculty, K. Maras, Turkey, 2Department of Orthopedics and Traumatology, Yuzuncu Yil University, Medical Faculty, Van, Turkey, ${ }^{3}$ Department of Pediatric Surgery, Kahramanmaras Sutcu Imam University, Medical Faculty, Kahramanmaras, Turkey, ${ }^{4}$ Department of Anesthesiology and Reanimation, Kahramanmaras Sutcu Imam University, Medical Faculty, Kahramanmaras, Turkey and ${ }^{5}$ Gaziantep Medical Center, Gaziantep, Turkey

Email: Ali Murat Kalender* - kalenderalimurat@hotmail.com; Ali Dogan - alidogan67@hotmail.com; Vedat Bakan - vedatbakan@hotmail.com; Huseyin Yildiz - dr.huseyinyildiz@mynet.com; Mehmet Ata Gokalp - doktorata@ hotmail.com; Mahmut Kalender - ortopedia34@hotmail.com

* Corresponding author
\end{abstract}

Published: 9 June 2009

Journal of Brachial Plexus and Peripheral Nerve Injury 2009, 4:6 doi:10.1 186/1749-722I-4-6

This article is available from: http://www.jbppni.com/content/4/I/6

(c) 2009 Kalender et al; licensee BioMed Central Ltd.

This is an Open Access article distributed under the terms of the Creative Commons Attribution License (http://creativecommons.org/licenses/by/2.0), which permits unrestricted use, distribution, and reproduction in any medium, provided the original work is properly cited.
Received: 22 April 2009

Accepted: 9 June 2009

\begin{abstract}
Background: Zofenopril is an antioxidant agent which has been shown to have beneficial effects in hypertension and heart failure. The aim of this study was to test the effects of Zofenopril on nerve regeneration and scarring in a rat model of peripheral nerve crush injury.

Methods: Twenty-one adult Sprague-Dawley rats underwent a surgical procedure involving right sciatic nerve crush injury. $15 \mathrm{mg} / \mathrm{kg}$ Zofenopril was administered orally to seven rats in group $Z$ for seven days. Seven rats in group $S$ received saline orally for seven days. Seven rats in the control group $C$ received no drug after crush injury. Fourteenth and 42 nd days after injury, functional and electromyography assessments of nerves were performed. Functional recovery was analyzed using a walking track assessment, and quantified using the sciatic functional index (SFI). After these evaluations, all rats were sacrificed and microscopic evaluations were performed.

Results: The Sciatic functional Index (SFI) in group $\mathrm{Z}$ on $14^{\text {th }}$ day is different significantly from group $S$ and group $C(p=0.037)$. But on $42^{\text {nd }}$ day there was no difference between groups $(p=$ 0.278). The statistical analyses of electromyelographic (EMG) studies showed that the latency in group $Z$ is significantly different from group $S(p=0.006)$ and group $C(p=0.045)$. But on $42^{\text {nd }} d a y$ there was no difference between groups like SFI $(p=0.147)$. The amplitude was evaluated better in group $Z$ than others $(p<0.05)$. In microscopic evaluation, we observed the highest number of nerve regeneration in the group $Z$ and the lowest in the group $C$. But it was not significant statistically.
\end{abstract}

Conclusion: Our results demonstrate that Zofenopril promotes the regeneration of peripheral nerve injuries in rat models. 


\section{Introduction}

Nerve injuries in extremity surgery occur usually by crush or tension type rather than incision or rupture. Orthopedic surgeons strive these type problems while treating long bone fracture and some times after surgical operations. Demyelinization and remyelinization, axonal degeneration and regeneration, focal, multifocal or diffuse nerve fiber loss and endoneural edema may be encountered due to crush injury [1-3]. It is also known that free oxygen radicals increase and cause tissue damage due to the tissue destruction after the injury $[3,4]$.

There is an extensive degeneration of the distal segment, known as Wallerian Degeneration after an axonal lesion [1]. The proximal stump that is connected to the cell body can regenerate to reinnervate the target organs especially in the peripheral nervous system. Although this process is often facilitated by a permissive environment in the periphery, some factors can impede normal return to function, such as the distance from injury site, metabolic disturbances, age and type of lesion [5-8]. Experimentally, a lot of medications were used in rat crush injury models such as steroids, nonsteroidal anti-inflammatory drugs and vitamins [9-11]. Some antioxidants such as Acetyl-L carnitine (ALCAR), FK506, polyethylene glycol (PEG) are used experimentally in treatment of nerve crush injuries [12-14].

Angiotensin-converting enzyme (ACE) inhibitors are drugs with different structures and activities used to treat heart failure and hypertension [15]. Zofenopril and captopril are the only ACE inhibitors with sulphydryl groups (SH) and consequent potential antioxidant activity [16]. This activity may contribute to the notable cardio- and endothelium protective effects of Zofenopril [17].

In this study, we have evaluated the effect of Zofenopril on functional recovery following sciatic nerve crush injury in rats.

\section{Methods}

The experimental protocols have been reviewed and approved by our University Animal Care and Ethic Committee. All efforts were made to minimize the number of animals used and their distress. 21 adult Sprague-Dawley rats weighing 250-275 g underwent unilateral (right) sciatic nerve crush. Test animals in group $Z$ received Zofenopril $(15 \mathrm{mg} / \mathrm{kg} /$ day for 7 days $)(\mathrm{n}=7)$, group $S$ received normal saline for 7 days following surgery $(\mathrm{n}=7)$, and group $\mathrm{C}$ control animals $(\mathrm{n}=7)$. The animals were kept in standard room conditions and fed with standard rat diet and water ad libitum.

All of the operations were performed under the microscope by same surgeon. The right lateral thigh was oper- ated, after shaving and preparing the skin with $10 \%$ povidone iodine. The sciatic nerve was exposed by opening the fascial plane between the gluteal and femoral musculature via a longitudinal incision. Under kethamine anesthesia, the sciatic nerve of 21 rats was exposed at midthigh level and either crushed for 30 seconds with a pair of jewelers forceps $(n=16)$. The wound was sutured in layers and the animals were allowed to recover.

At $2^{\text {nd }}$ and $6^{\text {th }}$ weeks, all animals were evaluated for sciatic functional index (SFI) by walking tract analysis (WTA) and electromyelography (EMG).

At 6 weeks after the evaluation, in order to confirm the nerve recovery, all animals were euthanatized by cervical dislocation. A 10-mm-long sample of the right sciatic nerve segment centered to the lesion was removed, fixed, and prepared for light and electron microscopic examination. From seven random of these rats, a 10-mm-long sample of the left sciatic nerve segment without any injury was removed, fixed, and prepared for histopathological examination and histomorphometry of myelinated nerve fibers.

\section{Walking tract analysis}

Functional recovery was analyzed using a WTA, and quantified using the sciatic functional index (SFI) [18]. Rats were tested at $14^{\text {th }}$ and $42^{\text {nd }}$ days after injury. Paw-prints were recorded by painting the hind paws with black ink and having them walk along an $8 \times 80 \mathrm{~cm}$ corridor, lined with white paper. The paw-prints were collected. Paw length and toe spread were measured. SFI was calculated according to the following Medinacelli formula [19]:

$$
\mathrm{SFI}=118.9\left[\frac{\mathrm{ETS}-\mathrm{NTS}}{\mathrm{NTS}}\right]-51.2\left[\frac{\mathrm{EPL}-\mathrm{NPL}}{\mathrm{NPL}}\right]-7.5
$$

Where ETS is the experimental toe spread, NTS the normal toe spread, EPL the experimental paw length, and NPL is the normal paw length.

\section{Motor nerve conduction velocity (MNCV)}

At the $14^{\text {th }}$ and $42^{\text {nd }}$ days after crush injury, the MNCV studies were performed under general anesthesia, and were carried out with a Neuromatic 2000 M/C NeuroMyograph (Dantec Elektronic Medicinsk Og Videnskabeligt Maleudstyr A/S, Skovlunde, Denmark). The sciatic nerve was percutaneously stimulated with supramaximal stimulus intensity through monopolar needle electrodes, proximal to the injury site at the level of the sciatic notch, and distal to the lesion at the level of the ankle. Square wave stimulus pulses of $500 \mu \mathrm{sec}$ in duration were delivered at $1 \mathrm{~Hz}$. Recorded signals were amplified with an alternating current-coupled preamplifier with filters at 1 $\mathrm{Hz}$ and $10 \mathrm{KHz}$. The latency of the evoked muscle action 
potentials were recorded from the intrinsic foot muscles with surface electrodes. Finally, the distance between the two sets of stimulating electrodes was measured on the skin with a ruler to the nearest $1 \mathrm{~mm}$, and the conduction velocity was calculated. Both experimental (right) and normal (left) nerves were measured.

\section{Morphological analysis}

The crushed sciatic nerves were immersed immediately just after sacrification in a drop of fixation solution, containing freshly prepared, ice cold $4 \%$ paraformaldehyde for an hour. Then, they were incubated at $0.5 \%$ saccharose solution in PBS buffer overnight. and embedded on cryomatrix (Shandon). $10 \mu \mathrm{m}$ thick transverse frozen sections were cut using a cryomicrotome (Leica, CM1900). Sections were kept in a humidified chamber with wet gauze. $10 \mu \mathrm{L}$ blocks solution, including $0.1 \%$ triton- $\mathrm{X}$, was added to each section. Panaxonal marker NE 14 (anti-nfh antibody) is used for immunhistochemical staining as primary and anti Mouse IgG 488 antibody as secondary. Macroscopical nerve evaluation has been performed according to regenerated axon number by immunoflourescent technique. The sections were analyzed using confocal microscope (Zeiss LSM 510 Meta). Crushed, proximal and distal to crushed area of the sciatic nerve were sectioned two times and the averages used for evaluation. They were compared for immunoreactivity with image analysis. Staining intensity of the crushed, proximal, distal regions were recorded as percentile. Each group of experimental rats analyzed statistically.

\section{Statistical Analysis}

The data were expressed as means \pm SD. Distributions of the data of the groups were assessed with one-sample Kolmogorov-Smirnov $\mathrm{Z}$ test and were found normal $(\mathrm{P}>$ 0.05 ). One-way analysis of variance (ANOVA) was performed on the data to examine differences among groups. If a significant group effect was found, a Tukey HSD test was used to identify the location of differences between groups. A p value less than 0.05 was statistically significant. Independent Student t test was used to compare EMG values of intact extremity and operated extremity.

\section{Results}

\section{Walking-track analysis}

The SFI was greatly decreased for both control and experimental groups 14 days post-injury, and began showing signs of recovery on day $42^{\text {nd }}$. The SFI values of group $\mathrm{Z}$ and $S(p=0.037)$ and $C(p=0.034)$ were significantly higher degree in the second week (Figure 1). At sixth week SFI values were close to each other in all groups. There was not a statistical difference between groups $(\mathrm{p}=0.278)$. SFI values for $2^{\text {nd }}$ and $6^{\text {th }}$ weeks are given in Table 1 and Table 2.

The EMG studies of the Subjects on the 14th day showed that right sciatic nerve has a severe injury according to left (intact) side that is statistically different (paired t test) ( $\mathrm{T}$ $=-3.31 \mathrm{P}=0.016)$.

The EMG measurement of rats in the second week for the latency significant degree between the groups are different $(\mathrm{p}=0.007)$. The latency in the $2^{\text {nd }}$ week of the group $\mathrm{Z}$ was significantly lower than group $\mathrm{S}(\mathrm{p}=0.006)$ and $\mathrm{C}(\mathrm{p}=$ 0,045 ) (Figure 2). But this difference disappeared in the $6^{\text {th }}$ week $(p=0,147)$. EMG results for 2 nd and $6^{\text {th }}$ weeks are given in Table 1 and 2 . The amplitude values are examined, similar to the latency, there was a significant difference between the groups $(\mathrm{p}<0,001)$ at $2^{\text {nd }}$ week, but not on the $6^{\text {th }}$ week $(p=0,374)$ (Figure 3$)$.

\section{Morphological analysis results}

In all groups, lesion area, the proximal and distal parts of the lesion were estimated microscopically. The number of the fibrils found decreased in the distal to lesion nerve in all groups (Figure 4). The lowest regenerated fibril number estimated in group $\mathrm{C}$, and highest in group $\mathrm{Z}$.

\section{Discussion}

Severe anatomical and functional disorders can be seen after peripheral nerve injury. This type of injury frequency is increasing with technology in industrialized societies. Nerve injuries in extremity represent usually by crush or tension type rather than incision or rupture in surgery or trauma. Spontaneous regeneration through the distal nerve stump with good functional return can be expected

Table I: EMG results for $2^{\text {nd }}$ week, *: Group $\mathbf{Z}$ is significantly different.

\begin{tabular}{|c|c|c|c|c|}
\hline & Zofenopril (Group Z) (n= 7) & $\begin{array}{l}\text { Saline (Group S) } \\
\qquad(\mathrm{n}=7)\end{array}$ & Control (Group C) $(n=7)$ & $P$ \\
\hline SFI (mean \pm sd, range) & $\begin{array}{c}-12.84 \pm 2.86 \\
{[(-16.92)-(-8.62)]}\end{array}$ & $\begin{array}{c}-22.88 \pm 5.03^{*} \\
{[(-32.88)-(-17.55)]}\end{array}$ & $\begin{array}{c}-23.02 \pm 10.53^{*} \\
{[(-39.5 \mathrm{I})-(-12.52)]}\end{array}$ & 0.019 \\
\hline Latency (msec, mean \pm sd, range) & $\begin{array}{l}1.51 \pm 0.28 \\
(1.10-1.90)\end{array}$ & $\begin{array}{c}2.08 \pm 0.23^{*} \\
(1.80-2.50)\end{array}$ & $\begin{array}{l}1.90 \pm 0.36^{*} \\
(1.40-2.40)\end{array}$ & 0.007 \\
\hline Amplitude $(\mathrm{mV}$, mean $\pm \mathrm{sd}$, range) & $\begin{array}{c}8.77 \pm 2.08 \\
(5.70-11.50)\end{array}$ & $\begin{array}{c}5.12 \pm 1.39 * \\
(3.60-7.90)\end{array}$ & $\begin{array}{c}4.94 \pm 1.34^{*} \\
(3.80-7.50)\end{array}$ & $<0.001$ \\
\hline
\end{tabular}


Table 2: EMG results for $6^{\text {th }}$ week,

\begin{tabular}{|c|c|c|c|c|}
\hline & Zofenopril (Group Z) (n= 7) & $\begin{array}{l}\text { Saline (Group S) } \\
\qquad(n=7)\end{array}$ & Control (Group C) $(n=7)$ & $P$ \\
\hline SFI (mean \pm sd, range) & $\begin{array}{c}-7.19 \pm 2.38 \\
{[(-12.28)-(-5.67)]}\end{array}$ & $\begin{array}{c}-9.50 \pm 3.35 \\
{[(-14.11)-(-5.53)]}\end{array}$ & $\begin{array}{c}-12.20 \pm 8.90 \\
{[(-31.74)-(-5.67)]}\end{array}$ & 0.278 \\
\hline Latency (msec, mean \pm sd, range) & $\begin{array}{l}1.33 \pm 0.23 \\
(1.00-1.60)\end{array}$ & $\begin{array}{l}1.70 \pm 0.31 \\
(1.40-2.20)\end{array}$ & $\begin{array}{l}1.60 \pm 0.46 \\
(1.20-2.40)\end{array}$ & 0.147 \\
\hline Amplitude $(\mathrm{mV}$, mean $\pm \mathrm{sd}$, range) & $\begin{array}{l}12.61 \pm 2.69 \\
(9.10-16.00)\end{array}$ & $\begin{array}{l}11.03 \pm 3.52 \\
(6.30-17.00)\end{array}$ & $\begin{array}{l}10.31 \pm 2.88 \\
(6.90-14.40)\end{array}$ & 0.374 \\
\hline
\end{tabular}

after this type of injury $[20,21]$. This type of nerve injuries are treated pharmacological agents instead of surgery.

For this purpose, many pharmacological agents are tried experimentally and successful results were reported [914]. However, these studies did not go beyond the experimental studies. The healing process after nerve injury is reduced mainly free oxygen radicals rather than inflammation and edema [2]. Therefore, in recent years many researchers started to stand on the antioxidant mechanism. Antioxidant materials contribute nerve regeneration via free oxygen radicals scavenging effect [22]. Antioxidant enzymes such as superoxide dismutase and catalase and GSH-Px are found in mammalian organisms and protect cells from toxic effects of free radicals. While free radicals production, lipid peroxidation develops on cell membrane and this can lead to final cell death. The protective antioxidant enzyme activity increases in response to free radical formation. There are many experimental studies available showing free radicals production and importance of lipid peroxidation on cell membrane injury in

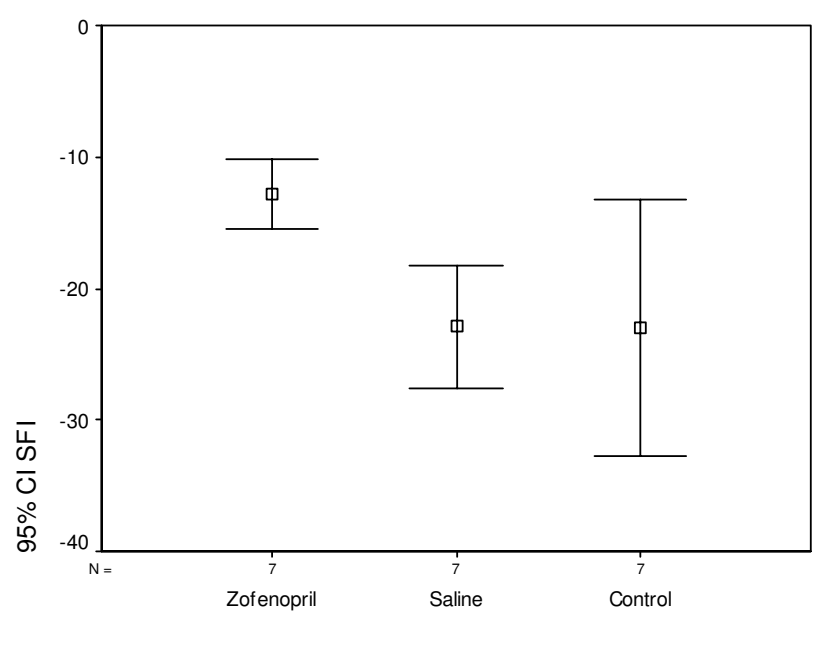

GROUP

\section{Figure I}

Sciatic function index (SFI) results for $2^{\text {nd }}$ week, $\mathrm{CI}$. Confidence intervale. nervous system injuries. Free radicals induced traumatic cell damage is basic mechanism of cell death. Nevertheless, catalase and GSH-Px traumatic damage such as the FOR cleaners provide partial improvement. [23]

Studies using the photo-oxidation of riboflavin sensitized by dianisidine to generate active oxygen species have clearly defined the remarkable difference in the antioxidant action of SH-containing compared with non-SHcontaining, ACE inhibitors [24]. The SH-containing, ACE inhibitors zofenopril, captopril, epicaptopril (the stereoisomer of captopril, which is devoid of ACE inhibitory properties) and fentiapril were found to be effective scavengers of non-superoxide free radicals, while four nonSH-containing ACE inhibitors were inactive. The protective effects from free radical-induced cell damage of $\mathrm{SH}$ containing ACE inhibitors have also been assessed in cultured endothelial cells exposed to a superoxide anion and hydroxyl radical generating system [25]. Pre-incubation of the cells with captopril, epicaptopril or zofenopril produced a concentration dependent $(10-200 \mu \mathrm{M})$ inhibi-

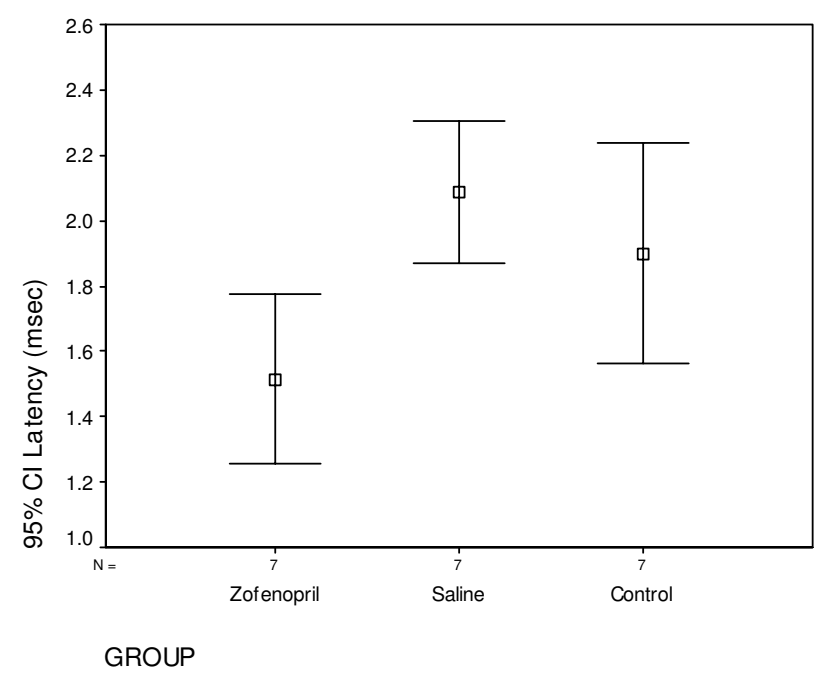

Figure 2

EMG results for $2^{\text {nd }}$ week, (latency), Cl. Confidence intervale. 


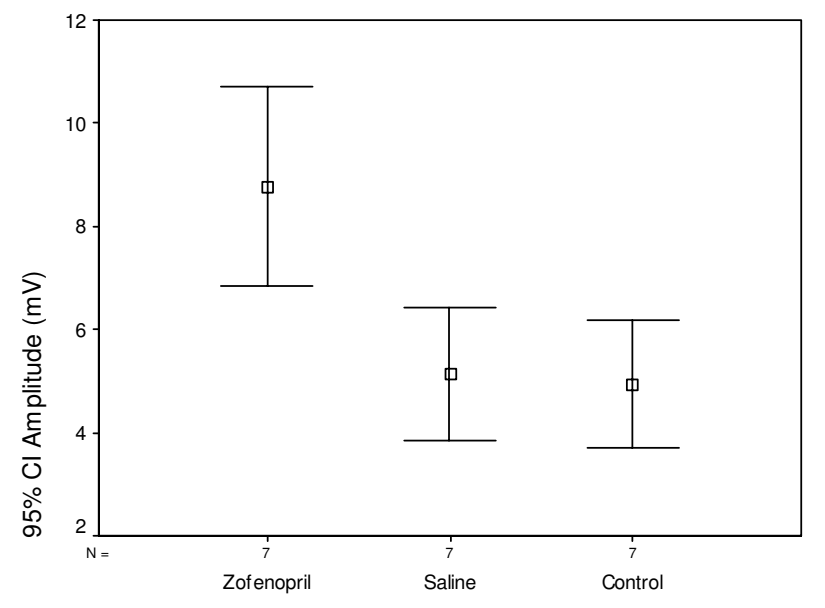

GROUP

Figure 3

EMG results for $2^{\text {nd }}$ week, (amplitude), $\mathrm{Cl}$. Confidence intervale.

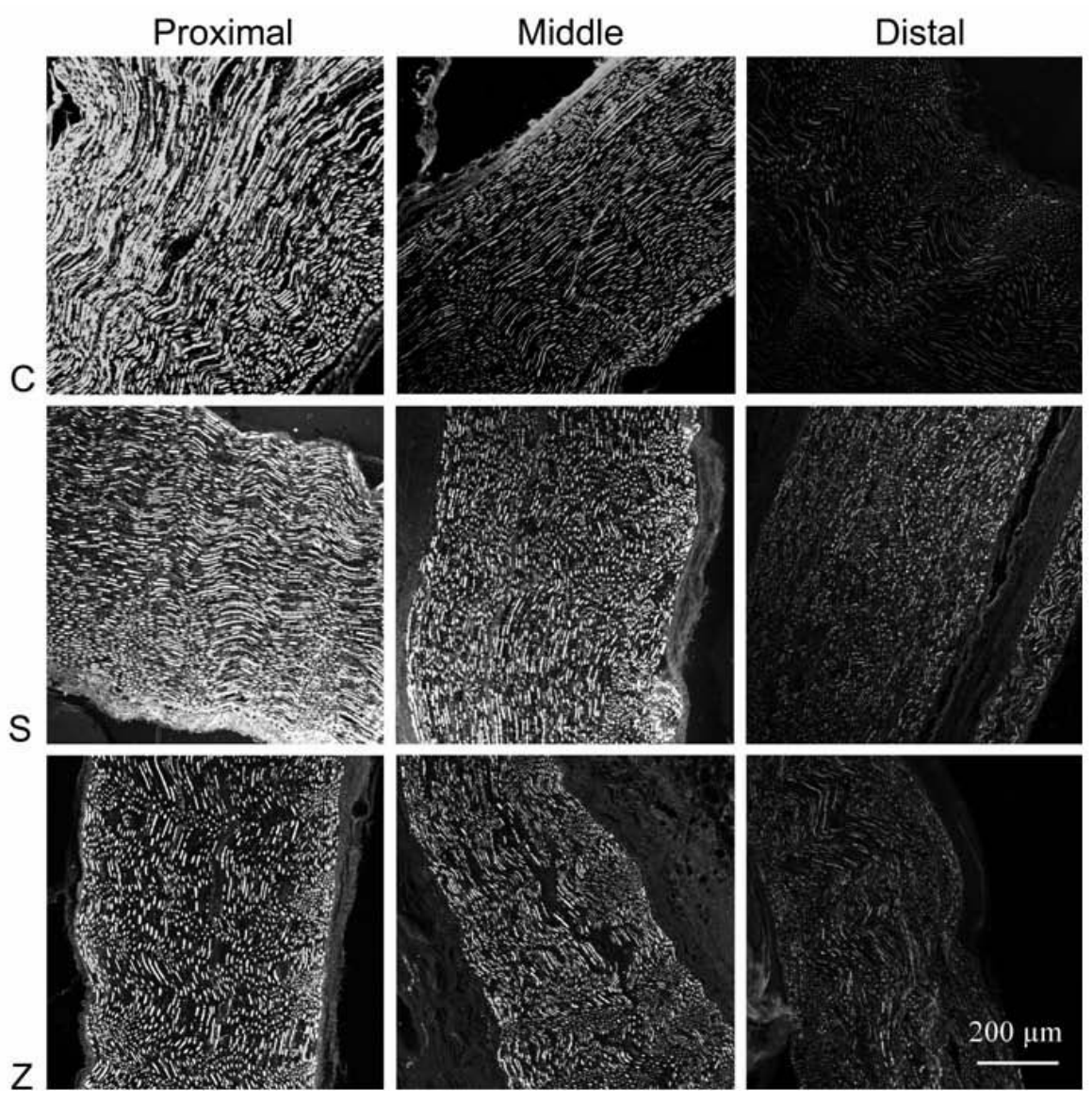

Figure 4

NFH immunoreactivity in the sections of proximal, middle (crush site) and distal parts of the sciatic nerves from animals in control (C), saline (S) and zofenopril (Z) groups. The lowest regenerated fibril number estimated in group $\mathrm{C}$, and highest in group $\mathrm{Z}$. 
tion of malonyldialdehyde formation. Both loss of cell viability and membrane blebbing were reduced by $\mathrm{SH}$ containing ACE inhibitors at concentrations as low as 10 $\mu \mathrm{M}$. In contrast, lisinopril and enalaprilat were ineffective at concentrations up to $200 \mu \mathrm{M}$.

Because of known antioxidant and free oxygen radicals scavenging effect of Zofenopril; it is used in experimental studies on ischemia-reperfusion damages in brain, kidney, heart and liver tissue $[26,27]$.

It has higher lipophilic effect than other ACE inhibitors with the long-term tissue penetration features tissue. Thus the long duration of effect is provided. In this way, and vascular tissue ACE myocardium and other drugs inhibition effects last much longer and has been shown to be effective [16].

Sunderland second-degree injury or axonotmesis means a breakdown of the axon and distal Wallerian degeneration but keeping of the continuity of the endoneural sheath. Spontaneous regeneration through the distal nerve stump with good functional return can be expected after this type of injury $[20,21]$. As the restored pattern of innervations is identical to the original, the study of this nerve lesion provides a good model for establishing the ontogeny of functional nerve recovery.

Electrophysiological, morphological and histologic studies were used for evaluation of experimental peripheric nerve regeneration [1-5]. But none of them was enough to determine the nerve recovery. Medinacelli at al. reported walking gait analysis for rat sciatic nerve. Later this method is modified and named as sciatic functional index [3].

The SFI increased and normal values were achieved at week 7 after sciatic nerve injury. Several authors reported nearly same results whose studies have also shown normal walking patterns only after the first month of post crush $[28,29]$. In contrast to these experiments, some authors reported a full recovery at the third and fourth weeks [30]. The difference in the rate of motor functional recovery may relate to the pathophysiologic response of peripheral nerves to the magnitude of different crushing loads [31].

In this study, the SFI in Zofenopril group was significantly higher than other groups in $2^{\text {nd }}$ week. We believe that this medication accelerates nerve crush injury healing in rats. Our findings in SFI and EMG studies in $2^{\text {nd }}$ week support this improvement. In the second week after injury and the EMG test results done in six weeks on the morphological analysis results support these findings.

\section{Conclusion}

As a result, Zofenopril has been found effective in promoting nerve regeneration in sciatic nerve crush injury rat model. These molecules can be used also for the human injured nerve but additional work is needed.

\section{Competing interests}

The authors declare that they have no competing interests.

\section{Authors' contributions}

AMK designed the study and performed experimental operations. $\mathrm{AD}$ and $\mathrm{VB}$ performed statistical analyses. $\mathrm{HY}$ and MAG had performed final operations and specimen collection of this experimental study. MK had performed linguistic and technical corrections. All authors read and approved the final manuscript.

\section{Acknowledgements}

The authors are grateful to Murat OZDEMIR, Ali CETINKAYA and Temel TOMBUL for the excellent artwork and their technical support.

\section{References}

I. Zochodne DW, Ho LT: Endoneural microenvironment and acute nerve crush injury in the rat sciatic nerve. Brain Res 1990, 535:43-48.

2. Bagdatoglu C, Saray A, Surucu HS, Ozturk H, Tamer L: Effect of trapidil in ischemia/reperfusion injury of peripheral nerves. Neurosurgery 2002, $51: 212-220$.

3. Arslan E, Milcan A, Unal S, Demirkan F, Polat A, Bagdatoglu O, Aksoy $A$, Polat $G$ : The effects of carnitine on distally burned dorsal skin flap: an experimental study in rats. Burns 2003, 29:221-227.

4. Stoll G, Muller HW: Nerve injury, axonal degeneration and neuronal regeneration: basic insights. Brain Pathol 1999, 9:313-325.

5. Gordon T, Sulaiman O, Boyd JG: Experimental strategies to promote functional recovery after peripheral nerve injuries. J Peripher Nerv Syst 2003, 8:236-250.

6. Kennedy JM, Zochodne DW: Impaired peripheral nerve regeneration in diabetes mellitus. J Peripher Nerv Syst 2005, I0:144-I57.

7. Verdu E, Ceballos D, Vilches JJ, Navarro X: Influence of aging on peripheral nerve function and regeneration. J Peripher Nerv Syst 2000, 5:191-208.

8. Lundborg G: Nerve injury and repair - regeneration, reconstruction and cortical repair. Philadelphia: Elsevier/Churchill Livingstone; 2004.

9. Al-Bishri A, Dahlin L, Sunzel B, Rosenquist J: Systemic betamethasone accelerates functional recovery after a crush injury to rat sciatic nerve. J Oral Maxillofac Surg 2005, 63:973-977.

10. Subbanna PK, Prasanna CG, Gunale BK, Tyagi MG: Acetyl salicylic acid augments functional recovery following sciatic nerve crush in mice. J Brachial Plex Peripher Nerve Inj 2007, 2:3.

II. Le Prell CG, Hughes LF, Miller JM: Free radical scavengers vitamins $A, C$, and $E$ plus magnesium reduce noise trauma. Free Radic Biol Med 2007, 42: I 454-I 463.

12. Wilson AD, Hart A, Brännström T, Wiberg M, Terenghi G: Delayed acetyl-L-carnitine administration and its effect on sensory neuronal rescue after peripheral nerve injury. J Plast Reconstr Aesthet Surg 2007, 60:1 I4-118.

13. Lee M, Doolabh VB, Mackinnon SE, Jost S: FK506 promotes functional recovery in crushed rat sciatic nevre. Muscle Nerve 2000, 23:633-640.

14. Ditor DS, John SM, Roy J, Marx JC, Kittmer C, Weaver LC: Effects of polyethylene glycol and magnesium sulfate administration on clinically relevant neurological outcomes after spinal cord injury in the rat. J Neurosci Res 2007, 85: |458-1467.

15. Brown NJ, Vaughan DE: Angiotensin-converting enzyme inhibitors. Circulation 1998, 97:1411. 
16. Subissi A, Evangelista S, Giachetti A: Preclinical profile of zofenopril: an angiotensin converting enzyme inhibitor with peculiar cardioprotective properties. Cardiovasc Drug Rev 1999, 17:115-133.

17. Borghi C, Ambrosioni E: Zofenopril: A review of the evidence of its benefits in hypertension and acute myocardial infarction. Clin Drug Invest 2000, 20:37I-384.

18. Bain JR, Mackinnon SE, Hunter DA: Functional evaluation of complete sciatic, peroneal, and posterior tibial nerve lesions in the rat, Plast. Plast Reconstr Surg. 1989, 83(1):129-I38.

19. de Medinaceli L, Freed WJ, Wyatt RJ: An index of the functional condition of rat sciatic nerve based on measurements made from walking tracks. Exp Neurol 1982, 77:634-643.

20. Seddon H: Three types of nerve injury. Brain 1943, 66:237-288.

21. Sunderland S: The anatomy and physiology of nerve injury. Muscle Nerve 1990, 13:77I-784.

22. Kurtoglu Z, Ozturk AH, Bagdatoglu C, Polat G, Aktekin M, Uzmansel D, Camdeviren H, Bagdatoglu O, Sargon M: Effects of trapidil after crush injury in peripheral nerve. Acta Med Okayama 2005, 59:37-44.

23. Ikeda T, Choi BH, Yee S, Murata Y, Quilligan EJ: Oxidative stress, brain white matter damage and intrauterine asphyxia in fetal lambs. Int / Dev Neurosci 1999, 17: I- 14.

24. Chopra M, Beswick H, Clapperton M, Dargie HJ, Smith WE, McMurray J: Antioxidant effects of angiotensin-converting enzyme (ACE) inhibitors: free radical and oxidant scavenging are sulfhydryl dependent, but lipid peroxidation is inhibited by both sulfhydryland nonsulfhydryl-containing ACE inhibitors. J Cardiovasc Pharmacol 1992, 19:330-340.

25. Mak IT, Freedman AM, Dickens BF, Weglicki WB: Protective effects of sulfhydryl-containing angiotensin converting enzyme inhibitors against free radical injury in endothelial cells. Biochem Pharmacol 1990, 40:2169-2175.

26. Cushman DW, Wang FL, Fung WC, Harvey CM, DeForrest JM: Differentiation of angiotensin-converting enzyme (ace) inhibitors by their selective inhibition of ACE in physiologically important target organs. Pharm Res 1992, 9: | 480- I 486.

27. Altunoluk B, Soylemez H, Oguz F, Turkmen E, Fadillioglu E: An Angiotensin-converting enzyme inhibitor, zofenopril, prevents renal ischemia/reperfusion injury in rats. Ann Clin Lab Sci 2006, 36:326-332.

28. Gudemez E, Ozer K, Cunningham B, Siemionow K, Browne E, Siemionow M: Dehydroepiandrosterone as an enhancer of functional recovery following crush injury to rat sciatic nerve. Microsurgery 2002, 22:234-24l.

29. Oliveira EF, Mazzer N, Barblerı CH, Sellı M: Correlation between functional index and morphometry to evaluate recovery of the rat sciatic nerve following crush injury: experimental study. J Reconstr Microsurg 200I, 17:69-75.

30. Bridge PM, Ball DJ, Mackinnon SE, Nakao Y, Brandt K, Hunter DA, Hertl C: Nerve crush injuries - a model for axonotmesis. Exp Neurol 1994, 1 27:284-290.

31. Rempel D, Dahlın L, Lundborg G: Pathophysiology of nerve compression syndromes: response of peripheral nerves to loading. J Bone Joint Surg Am. 1999, 8 I (II): 1600-1610.

Publish with Biomed Central and every scientist can read your work free of charge

"BioMed Central will be the most significant development for disseminating the results of biomedical research in our lifetime."

Sir Paul Nurse, Cancer Research UK

Your research papers will be:

- available free of charge to the entire biomedical community

- peer reviewed and published immediately upon acceptance

- cited in PubMed and archived on PubMed Central

- yours - you keep the copyright

Submit your manuscript here:

http://www.biomedcentral.com/info/publishing_adv.asp
BioMedcentral 